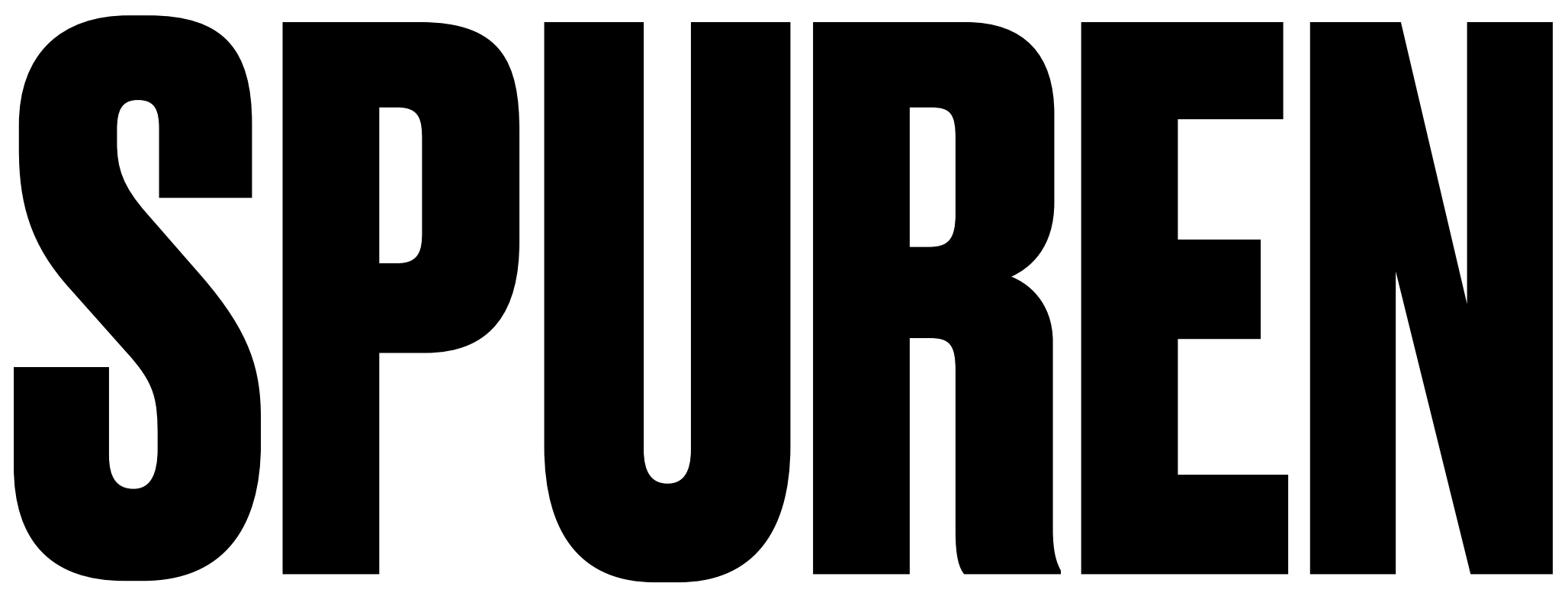




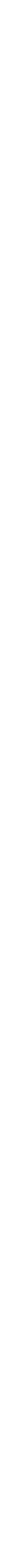




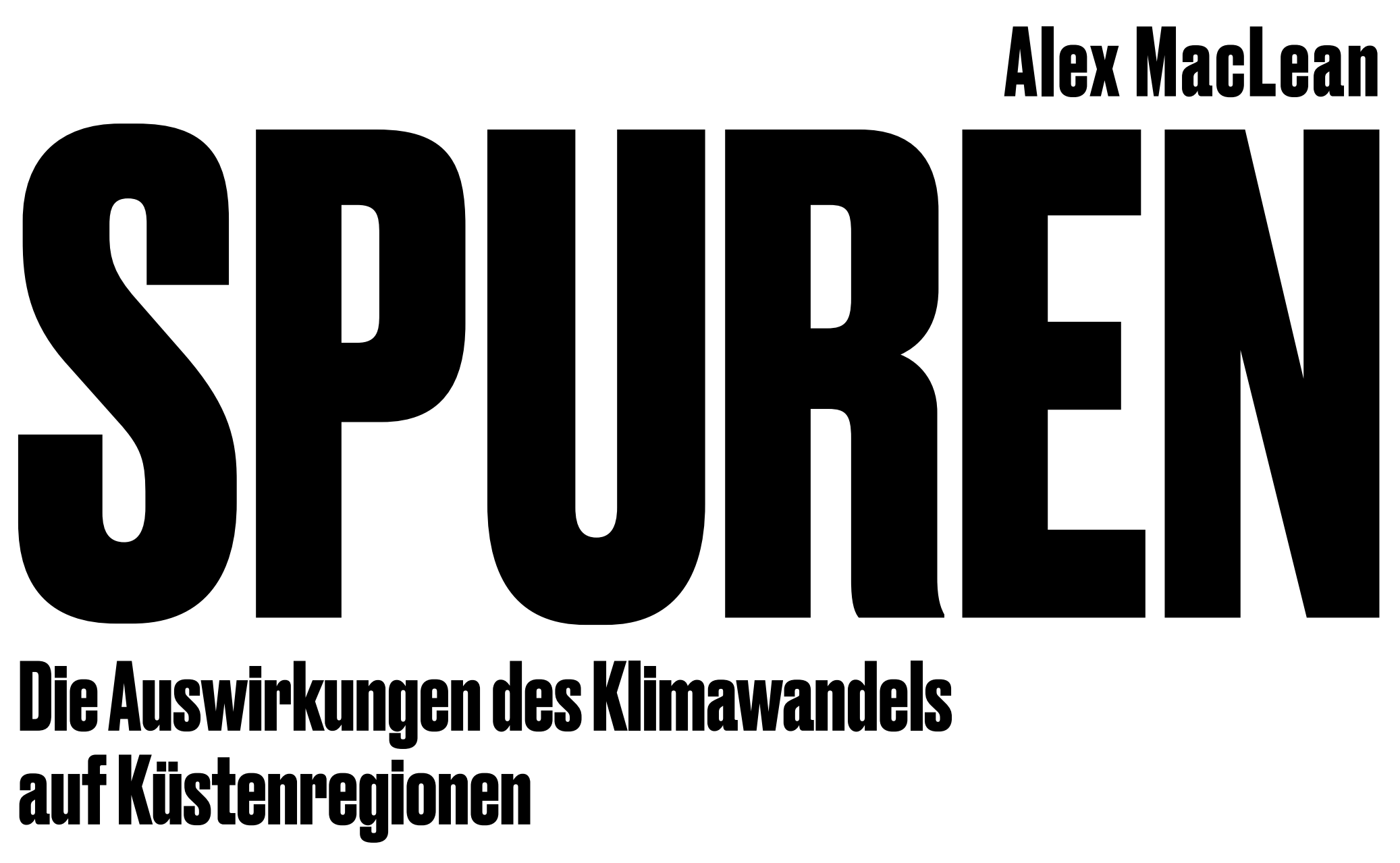

\section{Birkhäuser Basel}






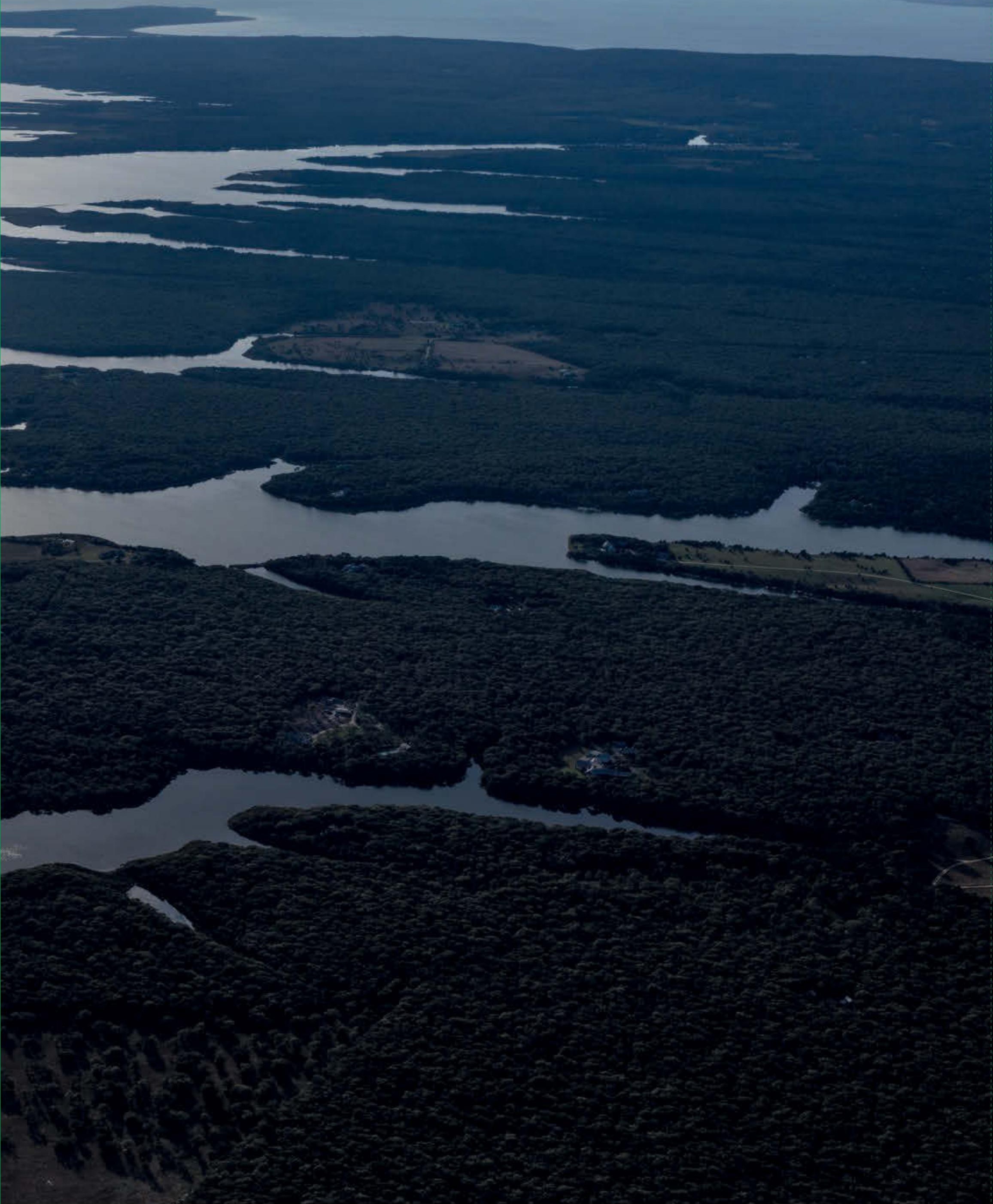
trennt. Dieser Strandwall (barrier beach) wird mehrmals im Jahr aufgerissen und schließt sich von selbst wieder. So fließt frisches Salzwasser in die Teiche und sorgt für eine gleichbleibende Wasserqualität. Das Bild zeigt, wie nah die langen, gewundenen Teichufer der riesigen Feuchtgebiete an die Strandküste heranreichen. 